\title{
Grape Pomace Skins and the Effects of Its Inclusion in the Technological Properties of Muffins
}

\author{
Ana B. B. Bendera, Caroline S. Speroni ${ }^{a}$, Paulo R. Salvador ${ }^{\mathrm{b}}$, Bruno B. Loureiro ${ }^{\mathrm{b}}$, \\ Naglezi M. Lovatto ${ }^{b}$, Fernanda R. Goulart ${ }^{\mathrm{b}}$, Marlene T. Lovatto ${ }^{c}$, Martha Z. Mirandad, \\ Leila P. Silva ${ }^{\mathrm{b}}$, and Neidi G. Penna ${ }^{\mathrm{a}}$

\begin{abstract}
aDepartment of Food Science and Technology, Federal University of Santa Maria, Santa Maria, RS, Brazil; bepartment of Animal Science, Federal University of Santa Maria, Santa Maria, RS, Brazil; 'Polytechnic College, Federal University of Santa Maria, Santa Maria, RS, Brazil; ${ }^{\text {Brazilian Agricultural }}$ Research Company (EMBRAPA Wheat) - Empresa Brasileira de Pesquisa Agropecuária (EMBRAPA Trigo), Passo Fundo, RS, Brazil
\end{abstract}

\begin{abstract}
The present study evaluated the incorporation of 5, 7.5, and $10 \%$ of Riesling skin flour (RSF) and Tannat skin flour (TSF) as wheat flour replacement in muffins. The flour was evaluated for gluten content and Alveograph parameters. The finished products were evaluated for chemical composition and technological properties, and a sensory analysis was performed. All samples presented higher dietary fiber content than wheat flour, and this was mainly in the form of soluble dietary fiber. The inclusion of grape skin flour decreased the lightness of the flour and increased the lightness values $\left(L^{*}\right)$ of the muffin crumbs and crusts. The hardness of the muffins that incorporated RSF and TSF muffins increased as the percentage of the skin flour increased. There was a decrease in the cohesiveness value as the skin flour percentage increased. Consumers did not perceive the levels of substitution. The results of the sensory analysis indicated that grape skin can be added to the ingredients of muffins without changing the color, taste, flavor, texture, and overall acceptability of the final product.
\end{abstract}

\section{ARTICLE HISTORY}

Received 17 February 2016

Revised 05 August 2016

Accepted 15 August 2016

\section{KEYWRODS}

By-product; dietary fiber; fiber concentration; sensory analysis; winemaking

\section{Introduction}

Grape pomace, the by-product of winemaking, consists mainly of grape skins and, in certain cases, seeds and stalks (Rondeau, Gambiera, Jolibert, \& Brosse, 2013). Millions of tons of grape residues are produced throughout the world on an annual basis. For example, in Brazil alone, the wine industry produces approximately 59 million $\mathrm{kg}$ of pomace (Campos, Leimann, Pedrosa, \& Ferreira, 2008) after fermentation each year. This represents a waste management issue both ecologically and economically (Fontana, Antoniolli, \& Bottini, 2013).

Agricultural by-products, such as grape pomace, have a renewable potential (Rondeau et al., 2013), and their use could deliver substantial economic 
benefits (Zhu, Du, Zheng, \& Li, 2015) due to their recovery and the value they consequently add.

Grape pomace contains some active compounds, such as antioxidants (e.g., phenolics) and large quantities of dietary fiber (DF). It has been reported that it contains DF content of more than 60\% (Zhu et al., 2015), of which the majority is mainly insoluble dietary fiber (IDF), such as cellulose and hemi-celluloses (Kammerer, Schieber, \& Carle, 2005). However, grape pomace also contains a significant amount of soluble dietary fiber (SDF), which has many health benefits due to the presence of water-soluble nonstarch polysaccharides such as $\beta$-glucans, pectins, and gums (MildnerSzkudlarz et al., 2011). The physiological effects of grape pomace are associated with its capacity to ferment in the large intestine, producing short chain fatty acids that increase viscosity and act as a prebiotic ( $\mathrm{Yu}$ \& Ahmedna, 2013). Soluble fiber can also reduce blood cholesterol and regulate blood glucose levels (Foschia, Peressini, Sensidoni, \& Brennan, 2013). The physiological effect of IDF is associated with its high porosity and low density, and its ability to increase fecal bulk and decrease intestinal transit (Yu \& Ahmedna, 2013). The use of grape pomace as a source of DF in food was reported by recent studies (Lavelli, Harsha, Torri, \& Zeppa, 2014; Pasqualone et al., 2014; Sant'Anna, Christiano, Marczak, Tessaro, \& Thys, 2014), and the results indicated that an increase in DF content in the developed products.

Due to consumer demand for healthier foods, the food industry is investing heavily in the development of new functional foods and ingredients (Pasqualone et al., 2014). The interest in foods with high fiber contents has led to the development of a large market for fiber-rich ingredients and products, such as muffins or similar types of cake, that are typically consumed at breakfast (Foschia et al., 2013). Muffins are sweet bakery products that can be quickly prepared (Baixauli, Sanz, Salvador, \& Fiszman, 2008), are appreciated by consumers of different age groups because of their taste and soft texture (Martínez-Cervera, Salvador, \& Sanz, 2015), and are normally consumed at breakfast (Foschia et al., 2013). The incorporation of apple pomace in cake (Sudha, Baskaran, \& Leelavathi, 2007) and peach dietary fiber (Grigelmo-Miguel, Carreras-Boladeras, \& Martin-Belloso, 2001) in muffins as a substitute for wheat flour have resulted in the development of novel products that have been proven to be accepted by consumers.

Fiber consumption continues to be below the recommended rate because of the lifestyle and habits of the population (Martínez-Cervera, Salvador, Muguerza, Moulay, \& Fiszman, 2011). A diet that is high in fiber often leads to a reduction in food intake and body weight because of its satiating effect (Moulay et al., 2006).

When developing foods are enriched with fiber, it is necessary to evaluate the effects that incorporating fiber has on consumer's perceptions of texture 
(Cappa et al., 2015), color, and acceptability. For example, the baking properties of some goods can be significantly affected when part of the wheat flour is replaced with ingredients that are rich in DF. Such effects include a reduction in loaf volume or height, and changes in texture (increases hardness of crumb, loss of crispiness), appearance (color, surface properties, density), and taste (Foschia et al., 2013).

In this context, the aim of the present study was to evaluate the effects that incorporating Riesling and Tannat grape pomace skins in the formulation of muffins had on taste, appearance, and texture. The nutritional, sensory and technological properties of the muffins were analyzed. The results indicated that the use of grape pomace skins in muffin recipes could represent a viable method of utilizing some of the waste products that result from the process of producing white wines (Riesling $\mathrm{cv}$.) and red wines (Tannat $\mathrm{cv}$.).

\section{Material and methods}

\section{Grape pomace skins-Dietary fiber concentration}

By-products from the wine industry were supplied by Vinícola Almadén (Santana do Livramento, RS, Brazil). The grapes, which had been harvested in 2014, consisted of two grape varieties: Tannat (red variety) and Riesling (white variety). These varieties were selected because they were determined to have a relevant fiber content. The pomace (skins and seeds) were dried by forced air at $55^{\circ} \mathrm{C}$ for 24 hours. The skins and seeds were separated with sieves: the dried pomace passed through a $3 \mathrm{~mm}$ sieve to reduce the particle size and then through a $0.2 \mathrm{~mm}$ sieve to separate the skin from the seeds (seeds were retained on the sieve). Both procedures were executed by manual rubbing. The skins were then ground (Marconi ${ }^{\circ}, 27.000$ RPM, particles < $1 \mathrm{~mm}$ ) and stored in plastic bags at $-18^{\circ} \mathrm{C}$ until use. Dietary fiber concentration was performed through a process of extraction using ethanol according to the process outlined by $\mathrm{Hu}$, Brown, and Labavitch (1996), with some modifications. The sample was immersed in boiling ethanol, in solvent: solute proportion (2:1), under agitation, for 30 minutes. After equilibrium (30 minutes), supernatant was discarded, and precipitate was twice reimmersed in ethanol (final concentration $80 \% \mathrm{v} / \mathrm{v}$ ). Finally, the supernatant was discarded, and the fibrous precipitate was dried by forced air at $40^{\circ} \mathrm{C}$ for 24 hours. The chemical composition of the grape pomace skins utilized in the present work (in $\mathrm{g} / 100 \mathrm{~g}$ on an dry matter basis), presented 10.53 of ash, 11.49 of crude protein, 2.72 of lipids, 52.21 of dietary total fiber, and 23.05 of carbohydrates for the Riesling variety; and 7.63 of ash, 20.21 of crude protein, 2.81 of lipids, 67.95 of dietary total fiber, and 1.4 of carbohydrates for the Tannat variety. 


\section{Muffin preparation}

Three muffin formulations were prepared for each grape pomace skin variety by replacing part of the wheat flour with grape pomace skin. The levels of replacement were established after preliminary tests (data not show) in which a product was developed that was deemed to offer satisfactory sensory (appearance, texture, and color) and technological properties (uniform texture and color and appearance similar to marketed products). The upper and lower levels represent the minimum and maximum grape skin flour can be added without changing the parameters described. A control formulation was also prepared. The samples were identified as control, 5\% RSF (5 g Riesling skin flour and $95 \mathrm{~g}$ wheat flour), 7.5\% RSF (7.5 g Riesling skin flour and $92.5 \mathrm{~g}$ wheat flour), $10 \% \mathrm{RSF}$ ( $10 \mathrm{~g}$ Riesling skin flour and $90 \mathrm{~g}$ wheat flour), $5 \%$ TSF ( $5 \mathrm{~g}$ Tannat skin flour and $95 \mathrm{~g}$ wheat flour), 7.5\% TSF (7.5 g Tannat skin flour and $92.5 \mathrm{~g}$ wheat flour) and 10\% TSF (10 g Tannat skin flour and $90 \mathrm{~g}$ wheat flour). Other ingredients were not changed. The muffin ingredients were wheat flour $(12.2 \mathrm{~g} / 100 \mathrm{~g}$ of moisture, $9.1 \mathrm{~g} / 100 \mathrm{~g}$ of protein) (Nordeste Alimentos, Brazil), pasteurized liquid egg yolk, and pasteurized liquid egg white (Fleischeggs, Brazil), milk (Cooperativa Santa Clara, Brazil), sugar (Açúcar Caravelas, Brazil), refined soy oil (IMCOPA S.A., Brazil), and baking powder (Royal S.A., Brazil) (Table 1).

The batter was prepared according to a recipe developed by MartínezCervera, Sanz, Salvador, and Fiszman (2012) with some modifications: The egg whites were whisked for 5 mins in a mixer (Arno, Brazil), at top speed. The sugar was mixed in for $1 \mathrm{~min}$ at top speed. Then, the egg yolk and half of the milk were added and mixed for 1 min at Speed 3. At the Speed 4, the rest of milk and oil were (gradually) added and then mixed for two more minutes. The wheat flour (or grape pomace skin flour depending on the formulation) was sieved and added slowly into the mixture alongside the baking powder. The batter was put in a pastry bag, and $45 \mathrm{~g}$ of the mixture was placed in each paper mold. An electric oven (Fischer, Brazil) was

Table 1. Muffin formulation-Control muffin and muffin prepared with inclusion of grape pomace skin flour as a wheat flour substitute.

\begin{tabular}{lccccccc}
\hline $\begin{array}{l}\text { Ingredients } \\
\text { (g/100 g flour) }\end{array}$ & Control & \multicolumn{1}{c}{$5 \%$} & $7.5 \%$ & $10 \%$ & $5 \%$ & $7.5 \%$ & $10 \%$ \\
\hline Wheat flour & 100 & 95 & 92.5 & 90 & 95 & 92.5 & 90 \\
RSF & - & 5 & 7.5 & 10 & - & - & - \\
TSF & - & - & - & - & 5 & 7.5 & 10 \\
Egg yolk & 30 & 30 & 30 & 30 & 30 & 30 & 30 \\
Egg white & 55 & 55 & 55 & 55 & 55 & 55 & 55 \\
Milk & 50 & 50 & 50 & 50 & 50 & 50 & 50 \\
Sugar & 80 & 80 & 80 & 80 & 80 & 80 & 80 \\
Oil & 35 & 35 & 35 & 35 & 35 & 35 & 35 \\
Baking powder & 2 & 2 & 2 & 2 & 2 & 2 & 2 \\
\hline
\end{tabular}

RSF: Riesling skin flour; TSF: Tannat skin flour. 
preheated for 25 mins at $170^{\circ} \mathrm{C}$, and the muffins were baked for $28 \mathrm{~min}$. The muffins were cooled at room temperature for 1 hour and stored in polypropylene bags until analysis.

\section{Physicochemical and rheological properties of wheat and grape pomace skin flour blends}

The flour and blend color were measured in a CR-400 colorimeter (Minolta Chroma Meter) in the CIE (Commission Internationale de l'Eclairage) $\mathrm{L}^{*} \mathrm{a}^{*}$ $\mathrm{b}^{*}$ color scale with $\mathrm{a} \mathrm{D}_{65}$ illuminant and $10^{\circ}$ viewing angle. The parameters measured were $L^{*}\left(L^{*}=0\right.$ [black], $L^{*}=100$ [white]), $a^{*}\left(+a^{*}\right.$ [red], $-a^{*}$ [green]), $\mathrm{b}^{*}\left(+\mathrm{b}^{*}\right.$ [yellow], $-\mathrm{b}^{*}$ [blue]). Falling number, gluten content, and Alveograph (rheological test), using AACC methods 56-81B, 38-12 and 54-30A (AACC, 2000), respectively, were performed. An Alveograph test was conducted in a Chopin Alveograph NG according to the standard method 54-30A (AACC, 2000). The parameters determined were tenacity or resistance to extension $(\mathrm{P})$, dough extensibility (L), curve configuration ratio $(\mathrm{P} / \mathrm{L})$, dough deformation energy or gluten strength $(\mathrm{W})$, and elasticity index (Ie).

\section{Muffin composition}

The moisture $\left(105^{\circ} \mathrm{C} / 12 \mathrm{~h}\right)$, ash $\left(550^{\circ} \mathrm{C} / 5 \mathrm{~h}\right)$, and crude protein (Kjeldahl method $-\mathrm{N} \times 6.25$ ) content of the muffins were determined according to the AOAC methods (2005). Lipid content was determined according to the Bligh-Dyer method (1959). Total and insoluble DF content was determined using an AOAC enzymatic-gravimetric method 991.43 (AOAC, 1995). The carbohydrate values were measured by calculating the differences in the total DF, lipids, protein, and ash contents (Chau \& Huang, 2003). The chemical composition results were expressed in $\mathrm{g} / 100 \mathrm{~g}$ of dry matter (DM).

\section{Technological properties of the muffins}

Each formulation was prepared twice on different days, and three muffins from each batch (six determinations) were used for the purposes of the analysis. Muffins were weighed before (W1) and after baking and cooling for 1 hour (W2), according to the method described by Martínez-Cervera et al. (2012). The weight loss at baking was calculated using the following equation:

$$
\text { Weight loss }=(\mathrm{W} 1-\mathrm{W} 2) * 100 / \mathrm{W} 1
$$

The muffin crumb and crust color were assessed using a CR-300 colorimeter (Minolta Ltd., Osaka, Japan) according to CIE $\mathrm{L}^{\star} \mathrm{a}^{\star} \mathrm{b}^{\star}$ and CIE $\mathrm{L}^{\star} \mathrm{C}^{\star}$ 
with a $\mathrm{D}_{65}$ illuminant and $10^{\circ}$ viewing angle. The muffin was cut in half on a plane parallel to its base, and the color of the crumb and crust were measured at several points. Three measurements were recorded directly on the samples. The parameters measured were the same as those used for flour and blend color.

Texture profile analysis (TPA) was performed in a TA-XTPlus Texture Analyzer (Stable Microsystems Ltd., Surrey, UK). Each formulation was prepared twice on different days, and four muffins from each batch (eight determinations) were used for the purposes of the analysis. The muffin (55 $\mathrm{mm}$ diameter, $10 \mathrm{~mm}$ height) was compressed with an aluminum cylinder probe of $75 \mathrm{~mm}$ in diameter $(\mathrm{P} / 75)$, and a double compression cycle test was performed at up to $50 \%$ compression. The conditions analyzed were pre-test speed $5 \mathrm{~mm} / \mathrm{s}$, speed $1 \mathrm{~mm} / \mathrm{s}$, and post-test speed $5 \mathrm{~mm} / \mathrm{s}$ (Martínez-Cervera et al., 2012). The parameters quantified from the curves were hardness, springiness, cohesiveness, chewiness, and resilience.

\section{Sensory analysis}

Muffin formulations were submitted at the acceptance test and purchasing intention. The present study was previously approved by the local Research Ethics Committee (31104214.3.0000.5346). Fifty-one consumers who had no previous training and who were aged between 17 and 55 participated in each test (72\% female, $28 \%$ male). Sensory analysis was conducted over the course of 2 days. On the first day, the tests were carried out with the muffins formulated with the white grape pomace skin inclusion and on the second day, with the red grape pomace skin inclusion. In the acceptance test, the muffin sample was evaluated for color, flavor, texture, taste, and overall acceptability on a 7 -point hedonic scale $(1=$ disliked very much; $7=$ liked very much). The samples were codified using three-digit numbers. Each consumer tasted three muffins that were randomly and separately offered to them. The purchasing intention test was carried out using a 5-point scale $(1=$ certainly will not buy it; $3=$ maybe will or will not buy it; $5=$ certainly will buy it).

\section{Statistical analysis}

The statistical description was performed by ANOVA, and the means of the samples were compared to those of the control via a Dunnet test. The acceptance test results were presented as the mean value with the standard deviation. For the sensory analysis, the samples were compared using the Tukey test. In both tests, the significance at $p<0.05$ was determined. The purchasing intention test was analyzed for the frequency test. 


\section{Results and discussion}

\section{Rheological and physicochemical properties of flour blends}

All the tested blends were darker than the control and this intensified as the percentage of grape skin flour increased. This could be attributed to the different colors of the grape raw materials, yellow-brown and purple, respectively (Table 2). RSF and TSF formulations showed increased $\mathrm{a}^{*}$ values, indicating a reddish color. In the RSF formulations, $\mathrm{b}^{\star}$ values also increased, while in TSF, these decreased, indicating a yellowish color.

For the Alveograph parameters, there was a decrease in the extensibility (L), and the highest value was found when $10 \%$ of the wheat flour was substituted with RSF. The fiber addition from a range of sources decreased the extensibility of the dough (Ktenioudaki \& Gallagher, 2012). The dough resistance to deformation $(\mathrm{P})$ increased with the inclusion of the grape pomace skins. Similar results were reported by Ayadi, Abdelmaksoud, Ennouri, and Attia (2009), which made an addition of cladodes from Opuntia ficus as the dietary fiber source. The higher level of Alveograph $p$-value (169 mm, for 10\% RSF) could be explained by the high level of water retention capacity for this grape variety, which results from the high amount of soluble dietary fiber. There was a reduction in the $\mathrm{W}$ values, which ranged from 91 to $178 \times 10^{-4} \mathrm{~J}$; the lowest values were found in the formulations with $10 \%$ of grape pomace skins, 96 and $91 \times 10^{-4} \mathrm{~J}$, Riesling and Tannat, respectively. For the cake formulation, as with the muffins, the ideal flour must present lower values for W (Gutkoski, Durigon, Mazzutti, \& Colla, 2011). The falling number (FN) is associated with flour enzymatic activity (the lower the value, the bigger the enzyme concentration). In the test formulations, there was a decrease in the FN values as the amount of RSF or TSF increased. This result may be explained by decreased levels of wheat

Table 2. Effect of Riesling and Tannat grape skin flour inclusion in the blend properties.

\begin{tabular}{|c|c|c|c|c|c|c|c|c|c|}
\hline \multirow[b]{2}{*}{ Samples } & \multicolumn{3}{|c|}{ Flour color } & \multicolumn{4}{|c|}{ Alveograph } & \multirow[b]{2}{*}{$\begin{array}{c}\text { Falling } \\
\text { number (s) }\end{array}$} & \multirow[b]{2}{*}{$\begin{array}{c}\text { Gluten } \\
\text { index }\end{array}$} \\
\hline & $L^{*}$ & $a^{*}$ & $b^{*}$ & $\begin{array}{c}W \\
\left(10^{-4}\right)\end{array}$ & $P(\mathrm{~mm})$ & $\mathrm{L}(\mathrm{mm})$ & $\mathrm{P} / \mathrm{L}$ & & \\
\hline Control & 94.48 & -0.55 & 8.63 & 178 & 100 & 43 & 2.34 & 352 & 97 \\
\hline $5 \% \mathrm{RSF}$ & $87.56 *$ & $1.65 *$ & $9.63 *$ & $171 *$ & $147 *$ & $26 *$ & $5.72 *$ & $342 *$ & 94 \\
\hline $7.5 \%$ RSF & $85.19 *$ & $2.34 *$ & $10.74 *$ & $160 *$ & $167 *$ & $21 *$ & $7.87 *$ & $334 *$ & $83.5 *$ \\
\hline $10 \%$ RSF & $83.80 *$ & $2.71 *$ & $11.33 *$ & $96 *$ & $169 *$ & $14 *$ & $12.11 *$ & $327 *$ & $90.5 *$ \\
\hline CV & 0.03 & 0.88 & 0.75 & 1.95 & 5.99 & 6.42 & 10.82 & 0.65 & 0.14 \\
\hline $5 \%$ TSF & 78.84* & $4.49 *$ & $1.81 *$ & $152 *$ & $140 *$ & $24 *$ & $5.85 *$ & $305 *$ & $81,5 *$ \\
\hline 7.5\% TSF & $75.08 *$ & $5.63 *$ & $1.11 *$ & $135 *$ & $142 *$ & $21 *$ & $6.76 *$ & $294 *$ & - \\
\hline $10 \% \mathrm{TSF}$ & $74.40 *$ & $5.99 *$ & $1.11 *$ & $91 *$ & $155 *$ & $15 *$ & $10.33 *$ & $289 *$ & 98 \\
\hline $\mathrm{CV}$ & 0.11 & 1.91 & 0.77 & 3.99 & 3.61 & 4.34 & 1.71 & 0.47 & 0.03 \\
\hline
\end{tabular}

* Statistically different $(p<0.05)$, in the same column, by Dunnett test, by variety.

-insufficient sample; RSF: Riesling skin flour; TSF: Tannat skin flour; $L^{*}=0$ (black), $L^{*}=100$ (white); $+a^{*}$ (red), - -a* (green); + b* (yellow), -b* (blue);W: gluten strength; P: resistance to deformation; L: extensibility; $\mathrm{CV}$ : Coefficient variation. 
flour; thus, enzymes were available to act in the grape skin flour. Gutkoski et al. (2011) described how the enzymatic activity for cakes, as with muffins, is not relevant because the fermentation is realized by the baking powder. All the results for the wet gluten were different to the control; there was a decrease in the values with increase the RSF and TSF inclusion.

\section{Muffin composition}

The ash content of the muffins that were produced with RSF and TSF were higher than the control due to the ash content present in the grape skins (10.53 and $7.63 \mathrm{~g} / 100 \mathrm{~g}$, respectively) (Table 3 ). As a result of the high protein content of TSF, only these muffins were different from the control. No differences between testing formulations and control were found in terms of lipids content. Grigelmo-Miguel et al. (2001) reported similar outputs to these results when orange bagasse was incorporated into muffins. All the testing samples (RSF and TSF) were different from the control in terms of total dietary fiber (TDF) content. The TDF content of the muffins produced with TSF increased as the levels of substitution increased. The IDF levels were highest in the muffins with TSF, with the same tendency of TDF. The main fiber present was the soluble type; there was an increase in SDF content, but only the batch containing $7.5 \%$ RSF was different from the control. Due to the increase in the DF levels of the testing formulations, the carbohydrate content was lower in the control. In general, the DF content of the muffins increased as the grape skin-flour ratio increased. The values were similar to those found by Walker, Tseng, Cavender, Ross, and Zhao (2014) in muffins that were prepared with grape pomace $(8.44 \mathrm{~g} /$ serving) and lower than the values found in muffins that contained orange bagasse (12.5 g/100 g DM) (Romero-Lopez, Osorio-Diaz, Bello-Perez, Tovar, \& Bernardino-Nicanor, 2011). Furthermore, all the muffins containing RSF and TSF may be considered to be "high in fiber." To claim a food is "high

Table 3. Chemical composition of muffins prepared by incorporating Riesling and Tannat grape skin flour as a wheat flour substitute ( $\mathrm{g} / 100 \mathrm{~g} \mathrm{DM})$.

\begin{tabular}{lllllllr}
\hline Samples & Ash & Protein & Lipid & TDF & IDF & SDF & Carb \\
\hline Control & 1.28 & 9.24 & 17.28 & 4.47 & 1.49 & 2.98 & 67.73 \\
$5 \%$ RSF & $1.45^{*}$ & 9.55 & 17.72 & $6.38^{*}$ & $3.05^{*}$ & 3.33 & $64.90^{*}$ \\
$7.5 \%$ RSF & $1.49^{*}$ & 9.60 & $18.16^{*}$ & $7.20^{*}$ & 1.37 & $5.83^{*}$ & $63.75^{*}$ \\
$10 \%$ RSF & $1.58^{*}$ & 9.08 & 17.70 & $6.81^{*}$ & $3.17 \&$ & 3.64 & $64.84^{*}$ \\
CV & 2.08 & 1.81 & 1.79 & 5.12 & 10.19 & 12.41 & 1.00 \\
$5 \%$ TSF & $1.43^{*}$ & $9.89^{*}$ & 16.14 & $6.09^{*}$ & $2.22^{*}$ & 3.87 & 66.45 \\
$7.5 \%$ TSF & $1.55^{*}$ & $9.75^{*}$ & 17.40 & $7.84^{*}$ & $3.68^{*}$ & 4.17 & $63.47^{*}$ \\
$10 \%$ TSF & $1.56^{*}$ & $9.94^{*}$ & 16.89 & $8.29^{*}$ & $4.71^{*}$ & 3.58 & $63.33^{*}$ \\
CV & 0.93 & 1.00 & 4.90 & 4.99 & 6.92 & 14.70 & 1.14 \\
\hline
\end{tabular}

* Statistically different $(p<0.05)$ in thesame column, by Dunnett test, by variety.

RSF: Riesling skin flour; TSF: Tansnat skin flour; TDF: Total dietary fiber; IDF: Insoluble dietary fiber; SDF: Soluble dietary fiber; CARB: Carbohydrate; CV: Coefficient variation. 
in fiber," it needs to contain at least $6 \mathrm{~g}$ per $100 \mathrm{~g}$ (or $3 \mathrm{~g}$ of fiber per $100 \mathrm{kcal}$ ) (European Commission, 2006).

\section{Muffin technologies properties}

The inclusion of grape skin flour decreased the lightness values $\left(\mathrm{L}^{*}\right)$ of the crumbs and crusts (Table 4). The increase in lightness was more noticeable in the TSF formulations than it was in the RSF formulations due to the color difference of the raw materials. This result can be explained by the increased concentration of pigments from the grape skin (Walker et al., 2014). The biggest change in color was observed in the muffins manufactured with TSF, and this was attributed to the dark purple color of Tannat cv. All the muffin crusts were darker than the muffin crumbs due to the effect of baking, during which Maillard reactions occurred (Martínez-Cervera et al., 2012). All the muffin crusts and crumbs tested were different to the control in terms of the $\mathrm{L}^{*}, \mathrm{a}^{*}$, and $\mathrm{b}^{*}$ values. The inclusion of RSF resulted in increased yellowness values in the crust and crumb, and this result can be explained by the yellow-brown color of the Riesling cv. Due to the inclusion of an ingredient that was rich in fiber and, consequently, had a significant hydration capacity, there was a minor weight loss in the formulations that incorporated RSF or TS.

Table 5 indicates that the replacement of wheat flour with RSF or TSF affected the hardness, cohesiveness, chewiness, and resilience of muffins. The control sample had a lower hardness than all other samples $(p<0.05)$. The $5 \%$ TSF muffin did not differ from the control. The hardness of the muffins formulated with RSF or TSF increased as the percentage of skin flour increased. The highest hardness value was found in the muffin containing 10\% TSF. The change in muffin texture may be related to the change in volume. Arora and Camire (1994) described how the addition of fruit skins in muffin formulations increased the muffin density and reduced air incorporation, thereby increasing the force needed to compress the sample (Chung, Lee, Han, \& Lim, 2010). Sudha et al. (2007) reported an increase in

Table 4. Effect of Riesling and Tannat grape skin flour inclusion in muffin color and weight loss.

\begin{tabular}{|c|c|c|c|c|c|c|c|c|c|}
\hline \multirow[b]{2}{*}{ Samples } & \multicolumn{4}{|c|}{ Crust } & \multicolumn{4}{|c|}{ Crumb } & \multirow[b]{2}{*}{ Weight loss (g) } \\
\hline & $L^{*}$ & $a^{*}$ & $b^{*}$ & C & L & $a^{*}$ & $b^{*}$ & C & \\
\hline Control & 49.32 & 20.60 & 36.0 & 41.48 & 80.30 & -3.62 & 33.54 & 33.79 & 14.19 \\
\hline $5 \%$ RSF & $45.28^{*}$ & $17.95^{*}$ & $31.25^{*}$ & $35.80^{*}$ & $60.80^{*}$ & $4.33^{*}$ & $22.34^{*}$ & $22.77^{*}$ & 13.38 \\
\hline 7.5\% RSF & $41.92^{*}$ & $17.26^{*}$ & $26.94^{*}$ & $32.02^{*}$ & $56.78^{*}$ & $5.65^{*}$ & $22.00 *$ & $22.71^{*}$ & 13.76 \\
\hline $10 \% \mathrm{RSF}$ & $36.11^{*}$ & $15.40^{*}$ & $19.92^{*}$ & $25.24^{*}$ & $54.00^{*}$ & $6.09 *$ & $21.51^{*}$ & $22.36^{*}$ & 14.31 \\
\hline $\mathrm{CV}$ & 6.19 & 3.71 & 10.11 & 7.69 & 1.39 & 7.97 & 1.79 & 7.69 & 6.91 \\
\hline $5 \%$ TSF & $39.51^{*}$ & $11.23^{*}$ & $20.57^{*}$ & $23.49 *$ & $44.62^{*}$ & $3.18^{*}$ & $7.21 *$ & $7.88^{*}$ & 13.80 \\
\hline 7.5\% TSF & $35.98^{*}$ & $10.43^{*}$ & $16.98^{*}$ & $19.37^{*}$ & $40.56^{*}$ & $4.62^{*}$ & $6.00 *$ & $7.57^{*}$ & 13.90 \\
\hline $10 \% \mathrm{TSF}$ & $32.27^{*}$ & $9.44^{*}$ & $12.92^{*}$ & $16.02^{*}$ & $36.69 *$ & $5.04^{*}$ & $4.59 *$ & $6.82 *$ & 13.44 \\
\hline CV & 5.23 & 4.51 & 7.62 & 5.43 & 1.17 & 10.91 & 3.36 & 5.43 & 6.90 \\
\hline
\end{tabular}

* Statistically different $(p<0.05)$ in the same column, by Dunnett test, by variety.

RSF: Riesling skin flour; TSF: Tannat skin flour; $L^{*}=0$ (black), $L^{*}=100$ (white); $+a^{*}$ (red), $-a^{*}$ (green); $+b^{*}$ (yellow), -b* (blue); C: Chroma; CV: Coefficient variation. 
Table 5. Effect of Riesling and Tannat grape skin flour inclusion in the muffin texture.

\begin{tabular}{lcclcc}
\hline Samples & Hard $(\mathrm{N})$ & Spring & Cohes & Chew $(\mathrm{N})$ & Res \\
\hline Control & 2.69 & 0.86 & 0.70 & 1.60 & 0.29 \\
$5 \%$ RSF & $3.22^{*}$ & 0.84 & $0.65^{*}$ & 1.76 & $0.27^{*}$ \\
$7.5 \%$ RSF & $3.32^{*}$ & 0.85 & $0.65^{*}$ & $1.82^{*}$ & $0.26^{*}$ \\
$10 \%$ RSF & $3.45^{*}$ & 0.86 & $0.62^{*}$ & $1.85^{*}$ & $0.26^{*}$ \\
CV & 10.96 & 2.65 & 3.64 & 9.85 & 5.58 \\
$5 \%$ TSF & 2.88 & 0.85 & $0.65^{*}$ & 1.57 & 0.27 \\
$7.5 \%$ TSF & $3.41^{*}$ & 0.85 & $0.62^{*}$ & 1.80 & $0.26^{*}$ \\
$10 \%$ TSF & $3.84^{*}$ & 0.84 & $0.61^{*}$ & $1.97^{*}$ & $0.26^{*}$ \\
CV & 14.22 & 3.44 & 3.90 & 10.69 & 6.47 \\
\hline
\end{tabular}

* Statistically different $(p<0.05)$ in the same column, by Dunnett test, by variety.

RSF: Riesling skin flour; TSF: Tannat skin flour; Hard: hardness; Spring: springiness; Cohes: cohesiveness; Chew: chewiness; Res: resilience; CV: Coefficient variation.

hardness as a result of increases in the levels of apple pomace as a replacement for wheat flour. Similar results were reported by Gómez, Moraleja, Oliete, Ruiz, and Caballero (2010), who reported how, when the percentage of fiber increased, the hardness of the muffins also increased. Similar to the present study, Zahn, Pepke, \& Rohm (2010) attributed the increased hardness of muffins that had been fortified with inulin to insufficient gel-forming ability. Smaller amounts of wheat flour resulted in lower water absorption due to the reduction in the amount of protein and starch. Therefore, during breadmaking, there is insufficient gel formation, which cannot be maintained after cooling by increasing the hardness of the final product.

The springiness values were similar to the results reported by Grigelmo-Miguel et al. (2001), in which an increase in hardness occurred although the springiness did not differ from that of muffins produced without the inclusion of dietary fiber.

The cohesiveness values for both the muffins produced with RSF and those produced with TSF were lower than the control. There was a decrease in the cohesiveness values as the skin flour percentage increased. Lower cohesiveness indicates that less energy is required during a second compression (Baixauli et al., 2008). All the samples tested presented higher chewiness than the control. No differences between the samples and the control were observed when wheat flour was replaced with either 5\% RSF or 5\% and 7.5\% TSF. Grigelmo-Miguel et al. (2001) reported a similar result when they found that increased levels of fiber increased the hardness and chewiness of muffins. All the samples had low resilience value, which is typical of formulations that contain sugar and fat; however, the only formulation that did not have a resilience value that was different to the control was the formulation with $5 \%$ RSF.

\section{Sensory analysis}

Observed higher fiber content in the formulations developed and recognized consequent sensory changes of the inclusions, followed with sensory 
analysis only in order to verify the incidence of acceptance among test formulations, and to validate the comparison, we used a study-designed crossover, with random distribution so that each trier sequentially receives the test formulations and acts as its own control. Thus, there was no significant difference in all sensory attributes (Table 6) across the muffins produced with TSF. This result demonstrates that grape skin can be added to muffin formulations without changing the color, taste, flavor, texture attributes, or the overall level of consumer acceptability. The incorporation of TSF changed the technological properties of the muffins in terms of color and texture; however, the sensory attributes were not changed for these samples. According to Bourne (1986), the texture parameter is a major factor in the rejection of a product; however, in the current study, the texture presented greater scores. For the TSF samples, the lowest acceptability score was found for the color. Walker et al. (2014) related that consumers usually see darker muffins as being healthier and containing more fiber or whole grains. This did not occur in our study. Levels of substitution were not perceived by consumers. There were significant differences in color and texture attributes and the overall acceptability of the muffins produced with RSF. The incorporation of yellow-brown flour influenced consumer acceptance; the 7.5\% RSF sample had the lowest score for color and texture attributes. In terms of purchasing intention, the muffins produced with RSF were situated in a score of 5 (certainly buy) and the TSF muffins were situated in a score of 4 (possibly buy). This indicates a favorable intention to buy these products (Figure 1). For both RSF and TSF muffins, the formulations with 5\% grape skin addition presented the highest scores, followed by the $10 \%$ formulation. A similar result was reported by Walker et al. (2014). This suggests that muffins that are fortified with $5 \%$ and $10 \%$ grape pomace are accepted by consumers.

In order to see how/if gender influenced the acceptability of the sensory tests, more statistical analyses were conducted. The ANOVA results of the sensory testing of the products formulated with TSF showed that the

Table 6. Means of acceptability-related attributes of muffins formulation prepared with the addition of Riesling and Tannat grape skin flour in different concentrations*.

\begin{tabular}{|c|c|c|c|c|c|}
\hline Attributes & Color & Flavor & Taste & Texture & Overall acceptability \\
\hline $5 \%$ RSF & $5.5 \pm 0.86^{\mathrm{a}}$ & $5.3 \pm 1.16^{\mathrm{ns}}$ & $5.7 \pm 1.07^{\mathrm{ns}}$ & $5.8 \pm 0.95^{\mathrm{a}}$ & $5.7 \pm 0.88^{\mathrm{a}}$ \\
\hline 7.5\% RSF & $4.9 \pm 1.02^{b}$ & $4.8 \pm 1.25^{\mathrm{ns}}$ & $5.2 \pm 1.18^{\text {ns }}$ & $5.1 \pm 1.11^{b}$ & $5.2 \pm 1.17^{b}$ \\
\hline $10 \%$ RSF & $5.3 \pm 1.16^{\mathrm{ab}}$ & $5.0 \pm 1.19^{\text {ns }}$ & $5.5 \pm 1.03^{\mathrm{ns}}$ & $5.6 \pm 0.80^{\mathrm{a}}$ & $5.6 \pm 0.91^{\mathrm{ab}}$ \\
\hline $5 \%$ TSF & $4.4 \pm 1.20^{\text {ns }}$ & $4.9 \pm 1.09^{\text {ns }}$ & $5.2 \pm 1.02^{\mathrm{ns}}$ & $5.3 \pm 1.07^{\text {ns }}$ & $5.2 \pm 0.96^{\mathrm{ns}}$ \\
\hline $7.5 \%$ TSF & $4.4 \pm 1.20^{\text {ns }}$ & $4.9 \pm 1.18^{\text {ns }}$ & $5.4 \pm 1.15^{\mathrm{ns}}$ & $5.4 \pm 1.06^{\mathrm{ns}}$ & $5.2 \pm 1.04^{\mathrm{ns}}$ \\
\hline $10 \%$ TSF & $4.4 \pm 1.20^{\text {ns }}$ & $5.0 \pm 1.05^{\text {ns }}$ & $5.4 \pm 1.00^{\text {ns }}$ & $5.4 \pm 1.02^{\mathrm{ns}}$ & $5.2 \pm 1.05^{\mathrm{ns}}$ \\
\hline
\end{tabular}

Different letters in the same column indicate statistical differences $(p<0.05)$ for the Tukey test, by variety. *Riesling and Tannat formulations were compared within each variety and not between varieties. RSF: Riesling skin flour; TSF: Tannat skin flour; ns: not significant. 

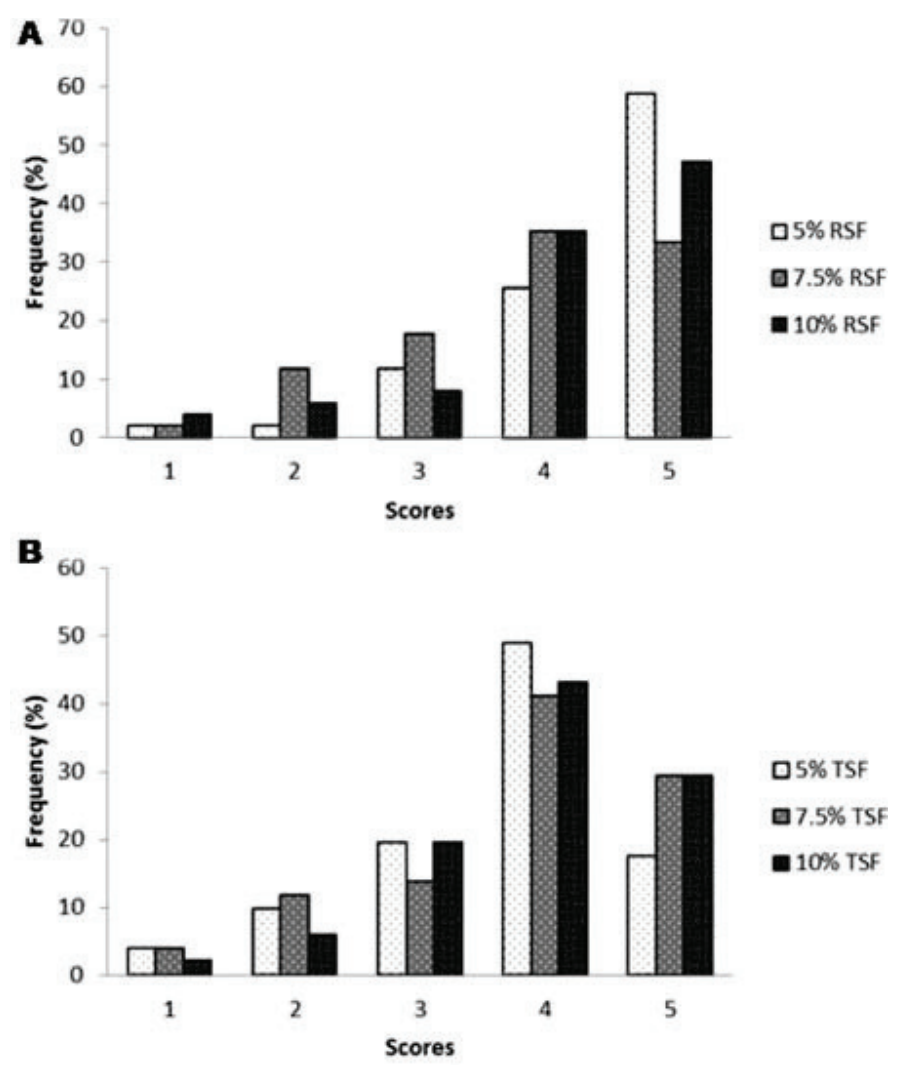

Figure 1. Purchasing intention for muffins prepared with the inclusion of Riesling (A) and Tannat (B) grape skin flour.

effect of the gender variable was only significant in terms of the acceptance of the color attribute, for which males accepted less than females $(p \leq 0.008)$.

No influence of the inclusion variable in the acceptance of the color and texture attributes and overall acceptability was identified for the muffins that were fortified with RSF. In terms of color, the formulation with $7.5 \%$ was less acceptable than that of $5 \%(p \leq 0.024)$, as compared to the overall acceptability $(p \leq 0.024)$. For the texture attribute, the formulation with $7.5 \%$ was accepted less than the 5\% $(p \leq 0.003)$ and $10 \%(p \leq 0.038)$ formulations. Gender variables influenced the acceptance to the aroma $(p \leq 0.030)$ and flavor ( $p \leq 0.028)$ attributes; the scores assigned by the male participants were higher than those assigned by the females. The gender and inclusion variables did not have any influence on purchase intention.

\section{Conclusions}

This study demonstrated that Tannat and Riesling grape skin flours may be used as an alternative to increase the DF content of muffins without having a negative effect on the sensorial properties of the products. The inclusion of 5 , 7.5 , and $10 \%$ ratios of these flours affected the texture, mainly the hardness, 
which increased as the levels of addition increased, color and TDF content, mainly SDF. The TDF content was twice that of the control as a result of the inclusion of $10 \%$ TSF, providing products with functional characteristics. Furthermore, the sensory analysis crossover indicated a good level of acceptability and confirmed that grape skin flour can be added at a level of 5\% and $10 \%$ for both Riesling and Tannat cultivars. These products are discarded by wineries; however, the results of this study indicate that there is potential added value of these by-products in terms of their ability to elaborate a product and nutritionally enrich it.

\section{Acknowledgments}

The authors would like to acknowledge Empresa Brasileira de Pesquisa Agropecuária (EMBRAPA Trigo) for color, falling number, gluten and alveography flour analysis.

\section{Funding}

The authors would like to acknowledge Coordenação de Aperfeiçamento de Pessoal de Nível Superior (CAPES) for scholarship and financial support.

\section{References}

AACC American Association of Cereal Chemists. (2000). Approved methods of the AACC (10th ed.). Methods. 08-01, 26-21A, 38-12, 46-12, 54-21, 54-30, 55-10 and 56-81B. St. Paul, MN: The Association.

AOAC International. (1995). Total, soluble and insoluble dietary fiber in foods. AOAC official method 991.43. Official methods of analysis (16th ed.). Arlington, VA: Author.

AOAC International. (2005). Official methods of analysis (16th ed.). Arlington, VA: Author.

Arora, A., \& Camire, M. E. (1994). Performance of potato peels in muffins and cookies. Food Research International, 27, 15-22. doi:10.1016/0963-9969(94)90173-2

Ayadi, M. A., Abdelmaksoud, W., Ennouri, M., \& Attia, H. (2009). Cladodes from Opuntia ficus indica as a source of dietary fiber: Effect on dough characteristics and cake making. Industrial Crops and Products, 30, 40-47. doi:10.1016/j.indcrop.2009.01.003

Baixauli, R., Sanz, T., Salvador, A., \& Fiszman, S. M. (2008). Muffins with resistant starch: Baking performance in relation to the rheological properties of the batter. Journal of Cereal Science, 47, 502-509. doi:10.1016/j.jcs.2007.06.015

Bligh, E. G., \& Dyer, W. J. (1959). A rapid method of total lipid extraction and purification. Canadian Journal of Biochemistry and Physiology, 37, 911-917. doi:10.1139/o59-099

Bourne, M. C. (1986). Food texture and viscosity: Concept and measurement. Geneva, NY: Cornell University, Academic Press.

Campos, L. M. A. S., Leimann, F. V., Pedrosa, R. C., \& Ferreira, S. R. S. (2008). Free radical scavenging of grape pomace extracts from Cabernet Sauvignon (Vitis vinifera). Bioresource Technology, 99, 8413-8420. doi:10.1016/j.biortech.2008.02.058

Cappa, C., Lavelli, V., \& Mariotti, M. (2015). Fruit candies enriched with grape skin powders: Physicochemical properties. LWT - Food Science and Technology, 62, 569-575. doi:10.1016/j.lwt.2014.07.039 
Chau, C. F., \& Huang, Y. L. (2003). Comparison of the chemical composition and physicochemical properties of different fibers prepared from the peel of Citrus sinensis L. Cv. Liucheng. Journal of Agricultural and Food Chemistry, 51, 2615-2618. doi:10.1021/ jf025919b

Chung, H. J., Lee, S. E., Han, J. A., \& Lim, S. T. (2010). Physical properties of dry-heated octenyl succinylated waxy corn starches and its application in fat-reduced muffin. Journal of Cereal Science, 52, 496-501. doi:10.1016/j.jcs.2010.08.008

European Commission. (2006). Regulation (EC) No 1924/2006 of the European Parliament and of the Council of 20 December 2006 on nutrition and health claims made on foods. Official Journal of the European Union, L404, 9-25.

Fontana, A. R., Antoniolli, A., \& Bottini, R. (2013). Grape pomace as a sustainable source of bioactive compounds: Extraction, characterization, and biotechnological applications of phenolics. Journal of Agricultural and Food Chemistry, 61(38), 8987-9003. doi:10.1021/ jf402586f

Foschia, M., Peressini, D., Sensidoni, A., \& Brennan, C. H. (2013). The effects of dietary fibre addition on the quality of common cereal products. Journal of Cereal Science, 58, 216-227. doi:10.1016/j.jcs.2013.05.010

Gómez, M., Moraleja, A., Oliete, B., Ruiz, E., \& Caballero, P. A. (2010). Effect of fibre size on the quality of fibre-enriched layer cakes. LWT-Food Science and Technology, 43, 33-38. doi:10.1016/j.lwt.2009.06.026

Grigelmo-Miguel, N., Carreras-Boladeras, E., \& Martin-Belloso, O. (2001). Influence of the addition of peach dietary fiber in composition, physical properties and acceptability of reduced-fat muffins. Food Science and Technology International, 7(5), 425-431. doi:10.1177/108201301772660484

Gutkoski, L. C., Durigon, A., Mazzutti, S., \& Colla, L. M. (2011). Influência do tipo de farinha de trigo na elaboração de bolo tipo inglês. Brazilian Journal of Food Technology, 14(4), 275-282. doi:10.4260/BJFT2011140400033

Hu, H., Brown, P. H., \& Labavitch, J. M. (1996). Species variability in boron requirement is correlated with cell wall pectin. Journal of Experimental Botany, 47, 227-232. doi:10.1093/ $\mathrm{jxb} / 47.2 .227$

Kammerer, D. R., Schieber, A., \& Carle, R. (2005). Characterization and recovery of phenolic compounds from grape pomace-A review. Journal of Applied Botany and Food Quality, 79, 189-196.

Ktenioudaki, A., \& Gallagher, E. (2012). Recent advances in the development of high-fibre baked products. Trends in Food Science \& Technology, 28, 4-14. doi:10.1016/j. tifs.2012.06.004

Lavelli, V., Harsha, P. S. C. S., Torri, L., \& Zeppa, G. (2014). Use of winemaking by-products as an ingredient for tomato puree: The effect of particle size on product quality. Food Chemistry, 152, 162-168. doi:10.1016/j.foodchem.2013.11.103

Martínez-Cervera, S., Salvador, A., Muguerza, B., Moulay, L., \& Fiszman, S. M. (2011). Cocoa fibre and its application as a fat replacer in chocolate muffins. LWT-Food Science and Technology, 44, 729-736. doi:10.1016/j.lwt.2010.06.035

Martínez-Cervera, S., Salvador, A., \& Sanz, T. (2015). Cellulose ether emulsions as fat replacers in muffins: Rheological, thermal and textural properties. LWT - Food Science and Technology, 63, 1083-1090. doi:10.1016/j.lwt.2015.04.067

Martínez-Cervera, S., Sanz, T., Salvador, A., \& Fiszman, S. M. (2012). Rheological, textural and sensorial properties of low-sucrose muffins reformulated with sucralose/polydextrose. LWT - Food Science and Technology, 45, 213-220. doi:10.1016/j.lwt.2011.08.001 
Mildner-Szkudlarz, S., Zawirska-Wojtasiak, R., Szwengiel, A., \& Pacyn'ski, M. (2011). Use of grape by-product as a source of dietary fiber and phenolic compounds in sourdough mixed rye bread. International Journal of Food Science and Technology, 46, 1485-1493.

Moulay, L., Ramos, S., Granado-Serrano, A. B., Muguerza, B., Bravo, L., \& Goya, L. (2006, June 12-14). Cholesterol lowering effect of a soluble hypercholesterolemic rats. In Proceedings Dietary Fiber Conference, Helsinki, Finland.

Pasqualone, A., Bianco, A. M., Paradiso, V. M., Summo, C., Gambacorta, G., \& Caponio, F. (2014). Physico-chemical, sensory and volatile profiles of biscuits enriched with grape marc extract. Food Research International, 65, 385-393. doi:10.1016/j.foodres.2014.07.014

Romero-Lopez, M. R., Osorio-Diaz, P., Bello-Perez, L. A., Tovar, J., \& Bernardino-Nicanor, A. (2011). Fiber concentrate from orange (Citrus sinensis L.) bagasse: Characterization and application as bakery product ingredient. International Journal of Molecular Sciences, 12, 2174-2186. doi:10.3390/ijms12042174

Rondeau, P., Gambiera, F., Jolibert, F., \& Brosse, N. (2013). Compositions and chemical variability of grape pomaces from French vineyard. Industrial Crops and Products, 43, 251254. doi:10.1016/j.indcrop.2012.06.053

Sant'Anna, V., Christiano, F. D. P., Marczak, L. D. F., Tessaro, I. C., \& Thys, R. C. S. (2014). The effect of the incorporation of grape marc powder in fettuccini pasta properties. $L W T-$ Food Science and Technology, 58(2), 497-501. doi:10.1016/j.lwt.2014.04.008

Sudha, M. L., Baskaran, V., \& Leelavathi, K. (2007). Apple pomace as a source of dietary fiber and polyphenols and its effect on the rheological characteristics and cake making. Food Chemistry, 104, 686-692. doi:10.1016/j.foodchem.2006.12.016

Walker, R., Tseng, A., Cavender, G., Ross, A., \& Zhao, Y. (2014). Physicochemical, nutritional, and sensory qualities of wine grape pomace fortified baked goods. Journal of Food Science, 79(9), 1811-1822. doi:10.1111/1750-3841.12554

Yu, J., \& Ahmedna, M. (2013). Functional components of grape pomace: Their composition, biological properties and potential applications. International Journal of Food Science and Technology, 48, 221-237. doi:10.1111/j.1365-2621.2012.03197.x

Zahn, S., Pepke, F., Rohm, H. (2010). Effect of inulin as a fat replacer on texture and sensory properties of muffins. International Journal of Food Science and Technology, 45, 2531-2537.

Zhu, F., Du, B., Zheng, L., \& Li, J. (2015). Advance on the bioactivity and potential applications of dietary fibre from grape pomace. Food Chemistry, 186, 207-212. doi:10.1016/j.foodchem.2014.07.057 